\title{
SUPRAORBITAL EYEBROW APPROACH TO SKULL BASE LESIONS
}

\author{
Yvens Barbosa Fernandes', Daniel Maitrot ${ }^{2}$, Pierre Kehrli², \\ Oswaldo Ignácio de Tella Jr', Ricardo Ramina', Guilherme Borges ${ }^{1}$
}

\begin{abstract}
We report our experience with a supraorbital eyebrow minicraniotomy. This technique is suitable to lesions situated in the region of the anterior fossa, suprasellar cisterns, parasellar region and Sylvian fissure. A $50 \mathrm{~mm}$ incision in the eyebrow and a supraorbital minicraniotomy is performed. Sixteem patients harboring different lesions were operated on with good postoperative and cosmetic results. We conclude that this approach is safe and useful in selected cases.
\end{abstract}

KEY WORDS: tumor, aneurysm, skull base, minimally invasive, surgical approach.

\begin{abstract}
Abordagem supra-orbitária superciliar de lesões da base do crânio
RESUMO - Reportamos nossa experiência com o uso de uma minicraniotomia supra-orbitária através do supercílio para tratamento de lesões situadas na fossa anterior, cisterna supra-selar, para-selar e fissura de Sylvius. Uma incisão de $50 \mathrm{~mm}$ é realizada no supercílio, seguida de minicraniotomia. Dezesseis pacientes portadores de diferentes lesões foram operados e apresentaram bom resultado pós-operatório e também estético. Concluímos que esse acesso é seguro e útil em casos selecionados
\end{abstract}

PALAVRAS-CHAVE: tumor, aneurisma, base do crânio, abordagem minimamente invasiva, acesso cirúrgico.

Usually tumors, aneurysms, and other lesions situated in the anterior or middle cranial fossae are approached by the standard classic pterional craniotomy ${ }^{1-3}$. Some other new techniques are also used to approach the orbit, anterior fossa and skull base ${ }^{4-9}$.

Recently Perneczky et al. ${ }^{10-12}$ have developed several supraorbital endoscopic "key-hole" approaches and demonstrated a good visualization of the socalled "suprasellar virtual pyramid". Combination of endoscopy and microneurosurgery permits the reduction of the size of the craniotomy required for good visualization of tumor or aneurysm and surrounding structures if compared to traditional techniques. We report our experience with a supraorbital eyebrow approach. We add to the description of our 16 cases some details on important landmarks. These landmarks are useful to preserve the frontotemporal branch of the facial nerve, the supraorbital and supratrochlear nerves in order to prevent cosmetic sequela of this easy and time-sparing procedure.

\section{METHODS}

Between December 1995 and May 2000, 16 patients were operated via the supraorbital approach (Table 1). Six patients at Hôpital Hautepierre, Strasbourg, France [Written permission given by Professor Daniel Maitrot (Head of the Neurosurgical Service of the Hautepierre Hospital)] and the remaining patients at the Hospital das Clínicas da UNICAMP, Campinas, Brazil [ Study approved by the Escola Paulista de Medicina Medical Ethics Committee]. The mean age was 46 years old (ranged $15-80$ years). There were ten women $(62.5 \%)$ and six men (37.5\%).

Preoperative CT (computerized topography), MR (magnetic resonance) and arteriography were accordingly used to select patients for this approach. In some cases an Aesculap $^{\text {TM }}$ set of endoscope and a Perneczky's neuroscope $^{\mathrm{TM}}$ were also used to give the surgeon a better endoscopic view of the operative field.

\section{Surgical Technique}

The patient is placed supine on the operative table, and the head is secured with a three-point skeletal fixation device. The position of the head changes depending

\footnotetext{
'Disciplina de Neurocirurgia da Faculdade de Ciências Médicas da Universidade Estadual de Campinas (UNICAMP) Campinas SP, Brasil; ${ }^{2}$ Hôpital Hautepierre, Strasbourg; França; ${ }^{3}$ Disciplina de Neurocirurgia da Escola Paulista de Medicina, Universidade Federal de São Paulo, São Paulo SP, Brasil.
}

Received 25 September 2001, received in final form 14 November 2001. Accepted 24 November 2001

Dr. Yvens Barbosa Fernandes - Rua José Teodoro de Lima 77/92 - 13015-150 Campinas SP - Brasil. E-mail: yvens@uol.com.br 
Table 1. Clinical findings and outcome of the 16 patients.

\begin{tabular}{cclcc}
\hline Case & Age/Sex & Pathology & Size & Complication \\
\hline 1 & $72, \mathrm{~F}$ & Tuberculum sella meningioma & 10 & None \\
2 & $52, \mathrm{M}$ & Craniopharyngioma & 20 & None \\
3 & $49, \mathrm{M}$ & Middle cerebral aneurysm & 15 & Fistula \\
4 & $75, \mathrm{~F}$ & Tuberculum sella meningioma & 16 & None \\
5 & $47, \mathrm{~F}$ & Craniopharyngioma & 20 & None \\
6 & $68, \mathrm{~F}$ & Bifurcation carotid aneurysm & 18 & Not clipped \\
7 & $46, \mathrm{M}$ & Frontobasal hematoma & 40 & Skin infection \\
8 & $80, \mathrm{M}$ & Frontobasal hematoma & 45 & None \\
9 & $15, \mathrm{~F}$ & Lymphocytic hypophysitis & 10 & Anosmia \\
10 & $32, \mathrm{~F}$ & Cavernous hemangioma & 25 & None \\
11 & $54, \mathrm{~F}$ & Pituitary adenoma & 28 & None \\
12 & $54, \mathrm{~F}$ & Optic nerve meningioma & 30 & None \\
13 & $17, \mathrm{~F}$ & Orbit myxoid sarcoma & 45 & None \\
14 & $42, \mathrm{~F}$ & Pituitary adenoma & 35 & None \\
15 & $17, \mathrm{~F}$ & Pituitary adenoma & 40 & None \\
16 & $20, \mathrm{M}$ & craniopharyngioma & 45 & None \\
\hline
\end{tabular}

on the lesion to be treated but in all cases it is placed above the level of the heart to improve venous drainage.

A 50-mm incision is done in the eyebrow, $5 \mathrm{~mm}$ above the orbital rim, right to the supraorbital notch just to 5 $\mathrm{mm}$ after the junction between the superior temporal line and the frontozygomatic suture (Fig 1). The orbicularis oculi muscle is carefully dissected and cut close to the orbital rim to avoid injuring the frontotemporal branch of the facial nerve (Fig 2).

One burr hole is placed under the most anterior extension of the superior temporal line, just above the frontozy-

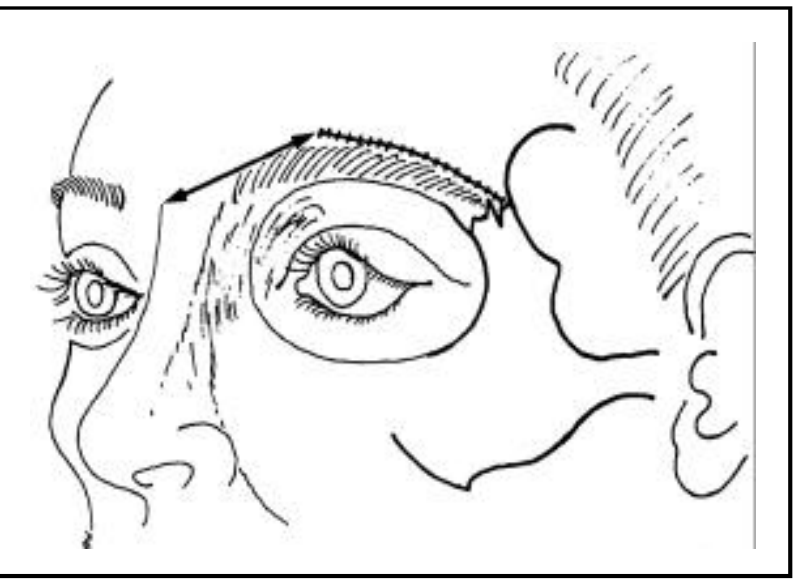

Fig 1. Skin incision made $22 \mathrm{~mm}$ off the midline or lateral to the supraorbital notch (double head arrow). gomatic suture (Key burr hole). The craniotome or drill is used to perform a supraorbital bone flap. After that, the posterior wall of the frontal bone is drill away to give a better basal view. In some cases the orbital roof is also removed. If the frontal sinus is opened, the mucosa is stripped off, the sinus is packed with betadine-soaked sponge and closed with a piece of the temporal muscle fascia.

The dura is incised horizontal and the frontal lobe is gently elevated with a retractor, allowing a good exposure of the anterior fossa, suprasellar cisterns and Sylvian fissure.

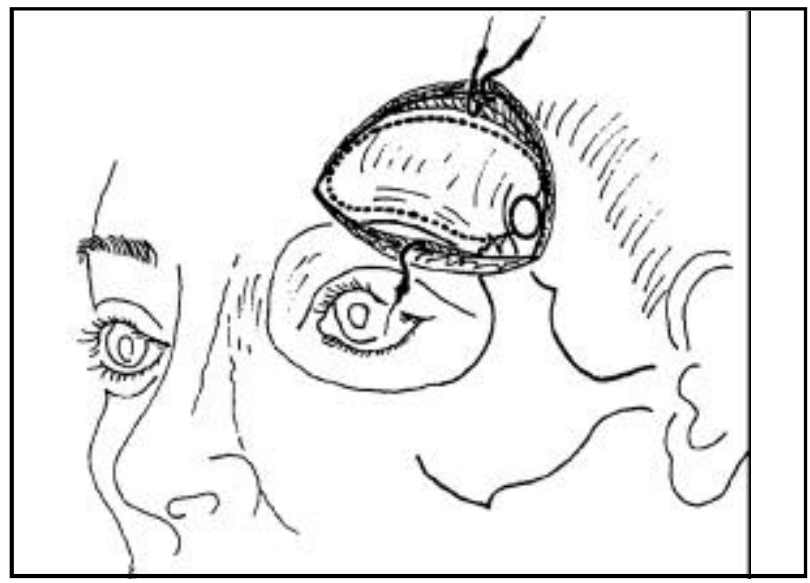

Fig 2. Subcutaneous and muscle flap turned upward. 


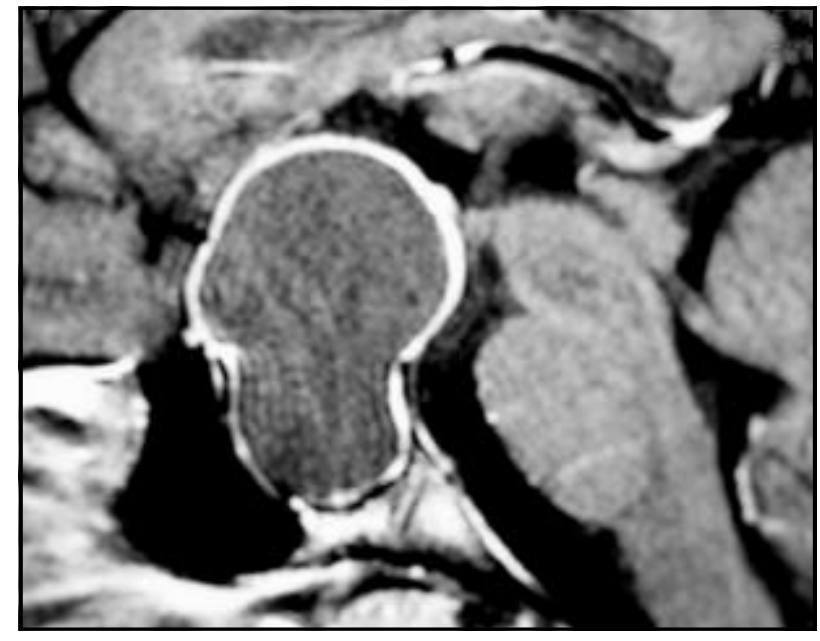

Fig 3. Preoperative gadolinium-enhanced $T_{1}$-weighted sagittal image showing a large cystic lesion on the sellar and suprassellar region.

After the surgical procedure running suture closes the dura. Some dural tack-ups are done and the bone is fixed.

The muscle and subcutaneous tissue are approximated and the skin is sutured by intradermic stitches.

\section{Illustrative case}

Case 16. A 20-year-old man was referred because of progressive loss of visual acuity and regression of secondary sex caracteristics in the last three years. A previous automated perimetry showed amaurosis of the left eye and temporal hemianopsia of the right eye. MR demonstrated a large sellar and suprasselar craniopharyngioma. The cystic portion was drained and part of the capsule was removed by this technique (Figs 3 and 4). The postoperative course was uneventful and there was improvement of his vision on the right eye.

\section{RESULTS}

There was no operative mortality or major neurological complications. One patient developed a rhinorrhea through a frontal sinus opening. He was reoperated and a patch of fascia lata was used to close the defect. Another patient had a fusiform aneurysm of the right carotid artery, which could not be clipped because of lack of definite neck. This aneurysm was wrapped with a piece of muscle and glue. The aneurysm with definite neck was successively clipped according to follow-up angiogram.

Two patients developed transient anesthesia over the frontal part of the scalp due to stretching of the supraorbital and supratrochlear nerves. One patient developed transient frontalis muscle palsy due to recoverable lesion of the frontotemporal branch of the facial nerve. One patient developed anosmia after the surgical procedure. Finally, in one alcoholic

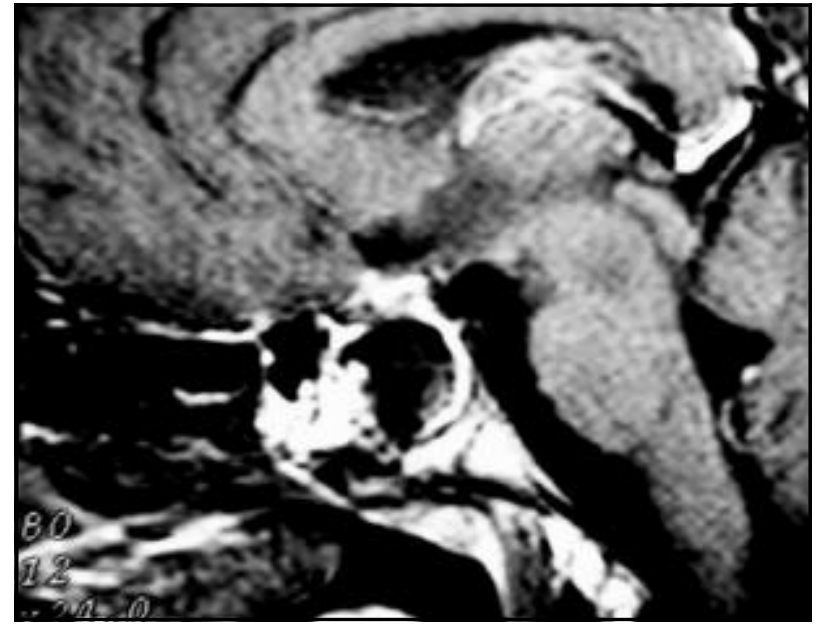

Fig 4. Postoperative gadolinium-enhanced $T_{1}$-weighted sagittal image after the surgical procedure.

patient it was necessary to remove the bone flap due to infection. Later this patient was submitted to a cranioplasty.

In each case, the supraorbital eyebrow approach allowed excellent visualization of the tumor, aneurysm or hematoma. A macroscopically complete removal of the tumors was obtained in all cases, except in the case of the optic nerve meningioma (in which a deliberated partial removal was planned) and one craniopharyngioma. The results were judged on postoperative CT or MR scans. The skin scar was considered cosmetically acceptable in all cases.

\section{DISCUSSION}

A precise knowledge of anatomic landmarks is important. Some landmarks should be borne in mind to avoid unnecessary damage to the nerves that pass close to the skin incision. Because this approach is a facial one, cosmetic problems must be anticipated. Palsy of the frontalis muscle or lesion of the supraorbital and supratrochlear nerves may be a handicap for the patient. The medial limit of the incision is 22 $\mathrm{mm}$ off the midline or lateral to the supraorbital notch. In most cases this will prevent section of the supraorbital and supratrochlear nerves ${ }^{13}$ (Fig 1).

Many authors have described anatomic landmarks to avoid injuring the frontotemporal branch during facial surgery ${ }^{14-17}$. Pitanguy and Ramos ${ }^{18}$ plotted the course of the frontotemporal nerve on the skin, as a line starting from a point $0.5 \mathrm{~cm}$ below the tragus and passing $1.5 \mathrm{~cm}$ above the lateral extremity of the eyebrow (Fig 5). The frontotemporal branch of the facial nerve passes near the skin incision. Pres- 


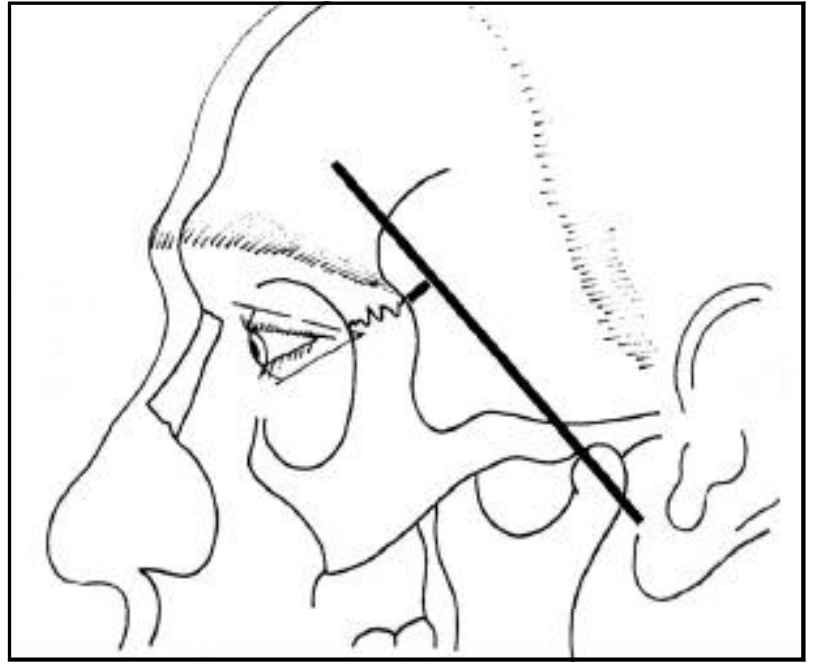

Fig 5. The course of the temporofacial nerve (long line), plotted on the skin as described by Pitanguy and Ramos. The short line shows its distance to lateral eyebrow (usually $15 \mathrm{~mm}$ ).

ervation of this branch is best done by cutting the orbicularis oculi muscle close to the orbital rim and turning the flap upward.

McArthur ${ }^{19}$, in 1912, reported an incision over the eyebrow, followed by trephination of the frontal bone and part of the orbital roof to treat lesions on the pituitary body and surrounding structures. Frazier ${ }^{20}$, in 1913, described an approach to the hypophysis through the anterior cranial fossa, emphasizing the resection of part of the supraorbital ridge to achieve a better basal view.

In 1920, Heuer ${ }^{21}$ developed the pterional approach to treat chiasmal lesions. This approach was later refined by Yasargil et al..$^{1-3}$, through removal of the sphenoid wing and orbital roof by a high speed drill. Jane et al. ${ }^{22}$ described a supraorbital approach to treat orbital tumors, aneurysms, pituitary adenomas and craniopharyngiomas. This technique was modified by Delashaw et al. ${ }^{6,7}$, by adding fracture and removal of the anterior orbital roof. Brock and Dietz ${ }^{23}$ developed a small frontolateral approach to treat intracranial aneurysms. Although this bone flap is similar to the supraorbital eyebrow approach, it is located more posteriorly and more laterally and the skin incision is done behind the hairline.

Recently, Perneczky et al. ${ }^{10-12}$, developed several endoscopic supraorbital approaches (key-hole surgery) and designed a new aneurysm clip with an inverted-spring to facilitate visual control during aneurysm surgery. They also describe the use of this approach to treat 197 aneurysms. The vast majority of the aneurysms (94\%) could be effectively clipped. Menovsky et al. ${ }^{24}$, described the supraorbital ap- proach combined to neuroendoscopy to treat aneurysm and tumor located in the interpeduncular fossa.

Fernandes et al. ${ }^{25}$, pointed out some anatomic landmarks to avoid damage to the supraorbital and supratrochlear nerves and also the frontotemporal branch of the facial nerve.

Czirják and Szeifert ${ }^{26}$ evaluated the results of 173 frontolateral keyhole minicraniotomies and stated that this is a safe approach for an experienced neurosurgeon to use in the treatment of supratentorial aneurysms or tumors of the anterior fossa and sellar regions.

More recently Shanno et al. ${ }^{27}$, developed an image-guided suprabrow approach to treat a series of 72 patients and concluded that this approach provides excellent exposure of the orbit, anterior fossa, and parasellar region. They had little significant morbidity and no mortality.

\section{CONCLUSION}

This technique represents an advance and an interesting option to the neurosurgical armamentarium. Due to the tremendous refinements of diagnostics methods, such as CT an MR, previously undetected lesions are now easily identified. The impact of this in an early diagnosis of small lesions for which large craniotomy seems to be unnecessary or inadvisable.

The advantages of this techniques are: 1) small skin incision; 2) minicraniotomy and low risk of bleeding and formation of hematomas; 3 ) good anatomic exposure of the structures located in the anterior fossa, suprasellar cisterns and Sylvian cistern; 4) smoother postoperative course; 5) cosmetically acceptable skin scar; 6) faster recovery; 7) diminished cost.

The disadvantages seem to be: 1) limited exposure; 2) scalp anesthesia due to section of the supraorbital and supratrochlear nerves; 3 ) frontalis muscle palsy due to section of the frontotemporal branch of the facial nerve; 4) fistula through a frontal sinus opening; 5 ) risk of visible skin scar.

We believe this technique is indicated in the treatment of lesions located in the anterior fossa, suprasellar cistern, parasellar and Sylvian fissure. It is not advisable to treat meningeomas located in the sphenoid wing or very large lesions that may not be totally visualized by this small keyhole approach. Care should be taken to forestall skin scar problems or damage to aforementioned nerves.

Acknowledgement - Part of this paper was previously published $^{25}$. The authors thank the gently granted permission given by Thieme Medical Publishers. 


\section{REFERENCES}

1. Yasargil MG, Fox JL. The microsurgical approach to intracranial aneurysms. Surg Neurol 1975;3:7-14

2. Yasargil MG, Antic J, Laciga R, Jain KK, Hodosh RM, Smith RD. Microsurgical pterional approach to aneurysms of the basilar bifurcation. Surg Neurol 1976;6:83-91.

3. Yasargil MG, Reichman MV, Kubik, S. Presevation of the frontotemporal branch of the facial nerve using the interfascial temporalis flap for pterional craniotomy: technical note. J Neurosurg 1987;67:463-466.

4. Al-Mefty O. Supraorbital-pterional approach to skull base lesions. Neurosurg 1987;21:474-477.

5. Al-Mefty O, Anand VK. Zygomatic approach to skull base lesions. J Neurosurg 1990;73:668-673.

6. Delashaw JB Jr, Jane JA, Kassel NF, Luce C. Supraorbital craniotomy by fracture of the anterior orbital roof. J Neurosurg 1993;79:615-618.

7. Delashaw JB Jr, Teceschi H, Rhoton AL. Modified supraorbital craniotomy: technical note. Neurosurg 1992;30:954-956.

8. Delfini R, Raco A, Artico M, Salvati M, Ciappetta P. A two-step supraorbital approach to lesions of the orbital apex. J Neurosurg 1992; 77:959-961.

9. Jonhs ME, Kaplas MJ, Jane JA, Park TS, Cantrell RW. Supraorbital rim approach to the anterior skull base. Laryngoscope 1984;94:1137-1139.

10. Perneczky A, Fries G. Use of a new aneurysm clip with inverted-spring mechanism to facilitate visual control during clip application. J Neurosurg 1995;82:898-899.

11. Cohen A, Perneczky A, Rodziewicz GS, Gingold SI. Endoscope-assisted craniotomy: approach to the rostral brain stem. Neurosurgery 1995;36:1128-1130.

12. Van Lindert E, Perneczky A, Fries G, Pierangeli E. The supraorbital keyhole approach to supratentorial aneurysms: concept and technique. Surg Neurol 1998;49:481-490.

13. Lang J. Clinical anatomy of the head. Neurocranium, orbit, craniocervical regions. Berlin: Springer Verlag,1983:32-72.
14. Liebman EP, Webster RC, Berger AS, Della Vecchia M. The frontalis nerve in the temporal brow lift. Arch Otolaryngol 1982;108:232-235.

15. Correia PC, Zani R. Surgical anatomy of the facial nerve as related to ancillary operations in rhytidoplasty. Plast Reconstr Surg 1973;52:549-552.

16. Ammirati M, Spallone A, Ma J, Cheatham M, Becker D. An anatomicrosurgical study of the temporal branch of the facial nerve. Neurosurgery 1993;33:1038-1044.

17. Ishikawa Y. An anatomical study on the distribuition of the temporal branch of the facial nerve. J Craniomaxillofac Surg 1990;18:287-292.

18. Pitanguy I, Ramos $\mathrm{S}$. The frontal branch of the facial nerve: the importance of its variations in face lifting. Plast Reconstr Surg 1966;38:353356.

19. McArthur LL. Asseptic surgical access to the pituitary body and its neighborhood. J Am Med Association 1912;58:2009-2011.

20. Frazier $\mathrm{CH}$. An approach to the hypophysis through the anterior cranial fossa. Ann Surg 1913,57:145-150.

21. Heuer GJ. Surgical experiences with an intracranial approach to chiasmal leisons. Arch Surg 1920;1:368-381.

22. Jane JA, Park TS, Pobereskin LH, Winn HR, Butler AR. The supraorbital approach: technical note. Neurosurg 1982;11:537-542.

23. Brock M, Dietz $\mathrm{H}$. The small frontolateral approach for the microsurgical treatment of intracranial aneurysms. Neurochirurgia 1978;21:185-191.

24. Menovsky T, Grotenhuis JA, Vries J, Bartels RHMA. Endoscope-assisted supraorbital craniotomy for lesions of the interpeduncular fossa. Neurosurgery 1999;44:106-110.

25. Fernandes YB, Maitrot D, Kehrli P. Supraorbital minicraniotomy. Skull Base Surg 1997;7:65-68

26. Cziják S, Szeifer G. Surgical experience with frontolateral keyhole craniotomy through a superciliary skin incision. Neurosurgery 2001;48:145150 .

27. Shanno G, Maus M, Bilyk J, at al. Image-guided transorbital roof craniotomy via a suprabrow approach: a surgical series of 72 patients. Neurosurgery 2001;48:559-568. 